Research Article

\title{
Optimal Proportion of Similar Materials and Rockburst Tendency of White Sandstone
}

\author{
Chaoyi Ma $\mathbb{D}^{2}{ }^{2}$ Zhengguo Zhu $\mathbb{D}^{1,3}{ }^{1,3}$ Zhichun Fang, ${ }^{2}$ Zhaobin Li, ${ }^{4}$ and Liu Liu ${ }^{2}$ \\ ${ }^{1}$ State Key Laboratory of Mechanical Behavior and System Safety of Traffic Engineering Structures, \\ Shijiazhuang Tiedao University, Shijiazhuang 050043, Hebei, China \\ ${ }^{2}$ Key Laboratory of Roads and Railway Engineering Safety Control (Shijiazhuang Tiedao University), Ministry of Education, \\ Shijiazhuang 050043, Hebei, China \\ ${ }^{3}$ Hebei Province Technical Innovation Center of Safe and Effective Mining of Metal Mines, Shijiazhuang 050043, Hebei, China \\ ${ }^{4}$ School of Civil Engineering and Architecture, Shandong University of Science and Technology, Qingdao 050043, \\ Shandong, China \\ Correspondence should be addressed to Chaoyi Ma; mcy@stdu.edu.cn and Zhengguo Zhu; zzg@stdu.edu.cn
}

Received 18 August 2021; Revised 10 October 2021; Accepted 7 December 2021; Published 26 December 2021

Academic Editor: Pasquale Gallo

Copyright (c) 2021 Chaoyi Ma et al. This is an open access article distributed under the Creative Commons Attribution License, which permits unrestricted use, distribution, and reproduction in any medium, provided the original work is properly cited.

\begin{abstract}
To explore the tendency of rockburst, a similar material ratio was optimised based on white sandstone. Quartz sand, iron powder, gypsum, cement, retarder, and a water-reducing agent were used as the main materials. The orthogonal test design principle was used to determine the four-factor and four-level orthogonal test design with the quartz sand content, iron powder content, gypsumcement ratio, and sand particle size as the influencing factors. Uniaxial compression tests and tensile tests were conducted on similar material models. The tensile strength and elastic modulus were analysed, the significance of each influencing factor was investigated, and the test results of the similar materials were fitted. The optimal ratios of the similar materials of white sandstone were found to be quartz sand content of $36 \%$, iron powder content of $1.9 \%$, gypsum-cement ratio of $1.8: 1$, and sand particle size of $2-4 \mathrm{~mm}$. The physical and mechanical properties of the similar materials were consistent with those of white sandstone. The mechanical properties of the similar materials were compared with those of the original rock. By judging the rockburst propensity and verifying the index, it is concluded that the similar materials can effectively simulate the characteristics of white sandstone, which is an ideal similar material of rockburst, and they all show strong rockburst propensity. The rock specimens with optimal proportions were produced, and the internal energy changes and rockburst mechanisms of the model at different temperatures were discussed. The results show that the rockburst process is closely related to energy, such as thermal energy and elastic strain energy, and the rock failure process can be divided into three main stages: energy accumulation, microcrack formation and propagation, and crack penetration and bursting. It provides an experimental basis for the preparation of rockburst similar materials that are more in line with the actual situation of the project and provides a basis for discussing the energy criterion of rockburst.
\end{abstract}

\section{Introduction}

Rockburst refers to the sudden release in strain energy accumulated in brittle rock masses, resulting in spontaneous failure of the rock. In deep underground spaces, it is relatively difficult to obtain an original rock. Field tests require considerable resources and effort, and it is impossible to accurately understand the stress changes and internal conditions generated in the surrounding rock. Therefore, many scholars at home and abroad have conducted research on rockburst similar materials.
Hu et al. [1] studied the changes in sandstone structure under microscopic conditions and examined the influence of water on the internal particles of sandstone. They discussed the development of sandstone cracks and studied the physical and mechanical properties of sandstone and the influence of water on rocks. Based on the similarity in the fracture process and energy consumption characteristics, Dai et al. [2] reported that the test curves before and after the peak were similar. They conducted a simulation test on the rockburst of the deep surrounding rock, thus laying the foundation of the rock mass similar material test. Li et al. [3] 
independently developed a physical test temperature field system and an excavation device and conducted a study on the rockburst characteristics of rockburst similar materials under thermomechanical coupling. The test showed that the model releases energy with rupture as the temperature increases. The greater the energy, the stronger the brittleness of the surrounding rock. Xu et al. [4] prepared rockburst similar materials composed of different proportions of aggregates, water-reducing agents, retarders, and other materials, and the most rock-burst-prone materials were selected from among them. The geometric characteristics of the rock under different loading methods and opening positions were studied, and the occurrence mechanism of rockbursts was investigated. Lu and Mao [5] investigated the propagation and effect of stress waves by simulating the behavior of similar materials in rocks. By controlling the magnitude of the stress waves, they monitored the number of cracks in the surrounding rock and found that rockbursts could be avoided to a certain extent by reducing the layered cracks. Wang et al. [6] studied the influence of temperature on rock masses, analysed and calculated the temperature field and stress, and obtained the changes in the internal stability of the rock mass with temperature changes, which indicates the direction for studying the stability of rock blocks under the influence of temperature. Simser [7] studied the influence of changes in the geological conditions on rockburst and used typical test methods to evaluate the level of rockburst. Deep hard rock mines were used as examples to discuss the necessity of process improvement for avoiding rockbursts, and effective solutions were provided for specific engineering problems. Jayasinghe et al. [8] used a high-temperature material model to simulate rockbursts and studied the influence of discontinuity and high ground stress on the evolution of damage caused by rock blasting. The study showed that blast-induced cracks tend to occur along the direction of high initial stress and the rock structure surface. The continuity and spatial distribution of rock will also have an important effect on the evolution of damage induced by rock blasting. Chen et al. [9] studied the mechanism of rock crack propagation through experiments, and the experimental results have a certain reference value for studying the mechanical properties of fractured rock masses under excavation and unloading conditions. Xu et al. [10] studied the ratio of a new type of rock-like material and through indoor model tests observed the crack propagation and the microscopic damage evolution process of the rocklike material with a single precrack at different inclination angles under uniaxial compression. A speckle damage variable based on the variation of the number of speckles is proposed to quantify the damage of the rock. Peng et al. [11] mainly studied the method of determining the crack closure stress and discussed the feasibility of using it to evaluate rock microcrack damage. Based on laboratory experiments, Cao et al. [12] studied the penetration mode between prefabricated cracks and the failure mode of multicrack specimens under uniaxial loading, as well as the penetration type and breaking law between mixed cracks under the combined action of compression and shear. Wang et al. [13] used the crack growth meter test system to measure the crack growth rate, at the same time introduced the tensile fracture softening damage model for numerical simulation, and thoroughly analysed the growth and evolution behavior of rock cracks under dynamic load through experiments.

Many scholars have studied the physical and mechanical properties of rockburst similar materials; however, research on similar material properties of different rock types needs to be improved. Although there are several articles on judging the rockburst propensity of similar materials, there are many types of deep underground rocks with different rockburst propensity indicators. Many factors affect the occurrence of rockburst, and the related mechanism is currently unclear. Therefore, this paper uses white sandstone as the prototype material to determine the similar material ratios and conducts an orthogonal experiment on the materials. According to the rockburst tendency judgement method [14], we examined whether the similar materials meet the rockburst characteristics of white sandstone and analysed the rockburst mechanism based on the energy theory under different temperature changes [15], which provides a reliable guarantee for subsequent tests. This study lays the foundation for research on the geometric characteristics of deep underground white sandstone and reveals the generation mechanism and evaluation method of rockbursts. This study can further improve the deficiencies in the study of rockburst failure characteristics and failure mechanisms under thermal-mechanical coupling conditions and provide a certain theory for rock mass excavation and construction under the same or similar geological conditions in actual engineering projects; it provides a new type of measure for real-time heating of rocks. Predicting rockburst through the energy release of rocks can effectively reduce the casualties and other losses caused by the suddenness and destructiveness of rockburst. It is important for ensuring the safety of construction personnel, ensuring the smooth progress of construction, and reducing economic losses.

\section{Tests Plan}

The ultimate goal of this experiment was to provide feasible similar materials for the study of the rockburst tendency of white sandstone. To ensure that the physical quantities of the model were similar, the similarity theory was adopted and the test procedures and methods for the conventional rockburst similar material were applied. Considering the similarity between the conventional physical and mechanical parameters, this test mainly considered the basic mechanical parameters of compressive strength $\sigma_{c}$, tensile strength $\sigma_{t}$, and elastic modulus $E$. The physical and mechanical properties of white sandstone were obtained by referring to previous research on the similar materials of sandstone [16] and conducting the uniaxial compression test and Brazilian split test. The results are shown in Table 1.

The material tested comes from the Daqian Shiling Tunnel. The Daqian Shiling Tunnel is located $5 \mathrm{~km}$ east of Jiangjiapuzi. The starting and ending mileage of the tunnel is DK69 + 225 DK71 + 685, and the total length of the tunnel is $2460 \mathrm{~m}$. According to geological survey and drilling, the internal distribution of the tunnel is mainly sandstone. 
TABLe 1: Physical and mechanical parameters of white sandstone covered by the study.

\begin{tabular}{lccc}
\hline Rock name & Compressive strength $\left(\sigma_{c} / \mathrm{MPa}\right)$ & Tensile strength $\left(\sigma_{t} / \mathrm{MPa}\right)$ & Elastic modulus $(E / \mathrm{GPa})$ \\
\hline White sandstone & 29.76 & 6.14 & 7.41 \\
\hline
\end{tabular}

2.1. Test Materials. To prepare the model materials that conform to the characteristics of rockbursts, this study conducted an orthogonal experiment based on existing research [17-19]. A similar material model conforming to the rockburst characteristics of white sandstone was used to study the rockburst tendency and rockburst mechanism of white sandstone under stress. To ensure that the prepared model material has the characteristics of white sandstone and can undergo obvious rockburst damage, quartz sand was used as the aggregate, gypsum and cement were used as the cementing material, and a small amount of iron powder was added to control the density of the material and make the specimen more consistent with those used in engineering practice. A small amount of water-reducing agent and retarder was added to prevent dry cracking of the test piece and to extend the gel time of the gypsum, respectively, while facilitating the preparation of the test piece. The materials used are shown in Figure 1.

2.2. Orthogonal Test Scheme. In this test, quartz sand content, iron powder content, gypsum-cement ratio, and sand particle size were used as the main influencing factors. Each influencing factor was designed at four levels, as listed in Table 2. Sixteen groups of experiments were designed, with three specimens prepared for each group in the experiment. The L16 $\left(4^{4}\right)$ orthogonal design table was selected. The range of each factor in the table was optimised based on previous studies $[16,18]$. The specific values are presented in Table 3.

2.3. Specimen Production. In this study, similar materials of white sandstone were prepared, and uniaxial compressive strength and tensile strength tests were carried out. The obtained mechanical parameters were used to determine the uniaxial compressive strength $\sigma_{c}$, tensile strength $\sigma_{t}$, and elastic modulus $E$ of the model and to ensure that the prepared white sandstone-like material model meets the physical and mechanical performance requirements of the original rock [20]:

(1) Prepare the raw materials by sieving quartz sand of different particle sizes to obtain quartz sand with particle sizes of $0.25-0.5 \mathrm{~mm}, 0.5-1 \mathrm{~mm}, 1-2 \mathrm{~mm}$, and $2-4 \mathrm{~mm}$ for the experiment.

(2) According to the orthogonal design table, a fixed proportion of quartz sand, iron powder, gypsum, cement, water, $1 \%$ retarder, and $1 \%$ water reducer is used.

(3) The measured test materials are mixed evenly and poured into a mould coated with petroleum jelly. A rubber hammer is used to pour the model specimens into layers to ensure that the specimens are dense.

(4) The poured model is stored under natural conditions and removed after $24 \mathrm{~h}$. The test blocks of

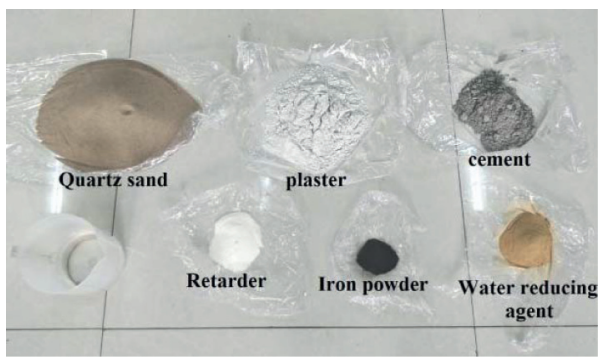

FIGURE 1: Similar material model of the test material covered by the study.

the similar materials are placed in the steam curing box for 28 days, and then a mechanical test is conducted. Figure 2 shows the sample preparation of similar materials. Figure 3 shows the maintenance of the specimens. Figure 4 shows the specimens after curing.

2.4. Compressive Strength Test. The cylindrical sample used in the test was $50 \mathrm{~mm} \times 100 \mathrm{~mm}$ in size (diameter $\times$ height), and the two ends of the test piece were smoothed with sandpaper so that the error due to parallelism at both ends was not more than $0.05 \mathrm{~mm}$ and the error of each section diameter was not more than $0.3 \mathrm{~mm}$. Sixteen groups of experiments are designed, and three specimens are prepared for each group of experiments, a total of 48 specimens. A TAW-2000 electrohydraulic servo rock testing machine was used to perform uniaxial compression tests on the specimens with similar material ratios, and the stress-strain curves of the specimens under compression were obtained. The uniaxial compressive strength was calculated according to equation (1). The specific tests were conducted as follows:

(1) Place the polished test piece vertically on the bearing plate of the testing machine so that both ends of the sample are in uniform contact with the surface of the upper and lower plates of the testing machine.

(2) Considering the problem of low material strength, the test adopts a loading rate of $0.1 \mathrm{MPa} / \mathrm{s}$ until the sample exhibits failure.

(3) Observe the damage to the sample after the test.

$$
\sigma_{c}=\frac{F}{A}=\frac{F}{\pi r^{2}}
$$

where $\sigma_{c}$ is the compressive strength $(\mathrm{MPa}), F$ is the load at failure of the specimen $(\mathrm{N}), A$ is the original area of the specimen $\left(\mathrm{mm}^{2}\right)$, and $r$ is the radius of the bottom surface of the specimen $(\mathrm{mm})$. The compressive strength testing process is shown in Figure 5. 
TABLE 2: Factor levels in orthogonal experimental design covered by the study.

\begin{tabular}{lcccc}
\hline Level & (A) Quartz sand (\%) & (B) Iron powder (\%) & (C) Plaster : cement & (D) Sand size (mm) \\
\hline 1 & 45 & 0.5 & $1: 1$ & $0.25-0.5$ \\
2 & 50 & 1 & $1.5: 1$ & $0.5-1$ \\
3 & 55 & 1.5 & $2: 1$ & $1-2$ \\
4 & 60 & 2 & $3: 1$ & $2-4$ \\
\hline
\end{tabular}

Table 3: Design table for orthogonal test covered by the study.

\begin{tabular}{lcccc}
\hline Level & (A) Quartz sand (\%) & (B) Iron powder $(\%)$ & (C) Plaster : cement & (D) Sand size (mm) \\
\hline L1 & 45 & 0.5 & $1: 1$ & $0.25-0.5$ \\
L2 & 45 & 1 & $1.5: 1$ & $0.5-1$ \\
L3 & 45 & 1.5 & $2: 1$ & $1-2$ \\
L4 & 45 & 2 & $3: 1$ & $2-4$ \\
L5 & 50 & 0.5 & $1.5: 1$ & $1-2$ \\
L6 & 50 & 1.5 & $3: 1$ & $2-4$ \\
L7 & 50 & 2 & $2: 1$ & $0.25-0.5$ \\
L8 & 50 & 0.5 & $2: 1$ & $0.5-1$ \\
L9 & 55 & 1 & $3: 1$ & $2-4$ \\
L10 & 55 & 1.5 & $1: 1$ & $1-2$ \\
L11 & 55 & 2 & $3: 1$ & $0.5-1$ \\
L12 & 55 & 0.5 & $2: 1$ & $0.25-0.5$ \\
L13 & 60 & 1 & $1.5: 1$ & $0.5-1$ \\
L14 & 60 & 1.5 & $1: 1$ & $0.25-0.5$ \\
L15 & 60 & 2 & $2-4$ \\
L16 & 60 & & $1-2$ \\
\hline
\end{tabular}

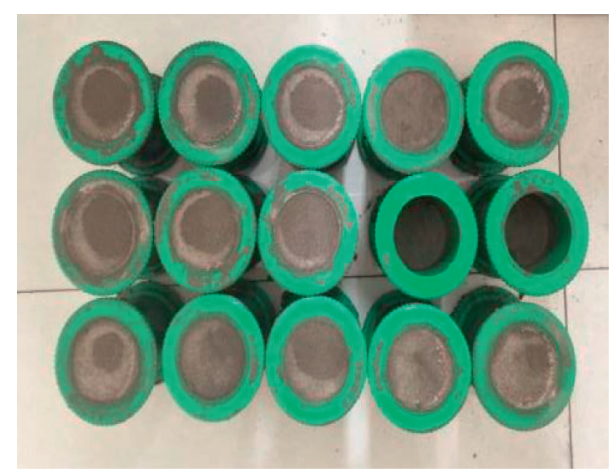

FIGURE 2: Sample preparation of similar materials covered by the study.

2.5. Tensile Strength Test. The test adopted a cylindrical sample of $50 \mathrm{~mm} \times 50 \mathrm{~mm}$ size (diameter $\times$ height). The Brazilian split test method was used to test the tensile strength of the rock. Sixteen sets of tests are designed, and each set of tests prepares three test pieces, a total of 48 test pieces. It was conducted on specimens with similar material proportions by using a TAW-2000 electrohydraulic servo rock testing machine, and the tensile strength of the specimens was calculated according to equation (2). The specific experimental steps are as follows:

(1) Fix the polished test piece on the split tensile fixture, and place the fixture on the testing machine so that both ends of the fixture are in uniform contact with the testing machine.

(2) Apply the loading rate of $0.1 \mathrm{MPa} / \mathrm{s}$ until the failure of the sample.

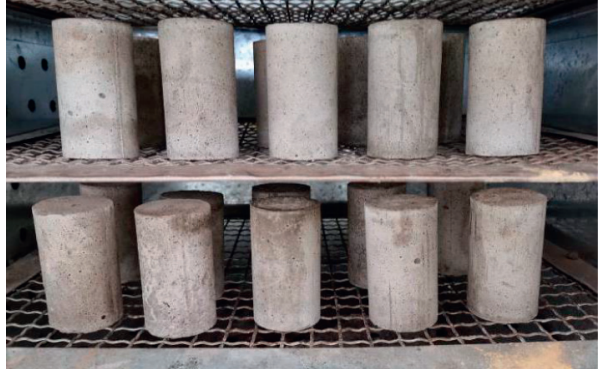

FIGURE 3: Maintenance of the specimens covered by the study.

(3) Observe the pattern of damage after testing.

$$
\sigma_{t}=\frac{2 P}{\pi d h}
$$

where $\sigma_{t}$ is the tensile strength (MPa), $P$ is the load when the specimen is broken $(\mathrm{N}), d$ is the diameter of the specimen $(\mathrm{mm})$, and $h$ is the height of the specimen $(\mathrm{mm})$. The Brazilian split test process is illustrated in Figure 6.

\section{Analysis of Test Results}

To obtain a clearer understanding of the influence of various materials on the mechanical properties of similar material models [21, 22], each index was calculated and analysed separately to obtain the extreme value of the influence of each factor on the test results.

The results of the orthogonal ratio are shown in Table 4.

The range analysis method involves calculating the difference between the maximum and minimum average 


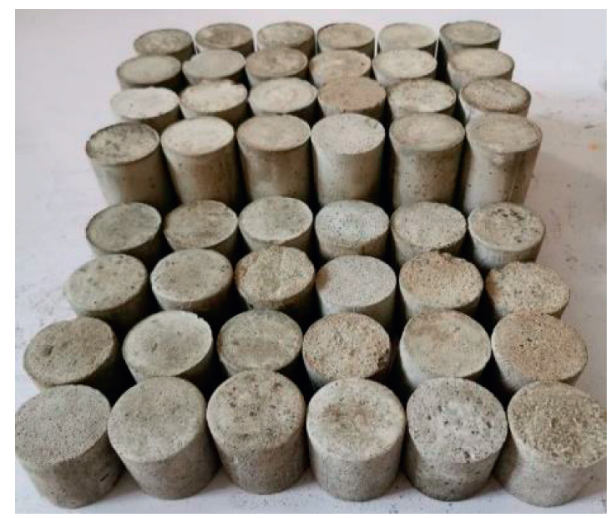

FIgURE 4: Partial standard specimen covered by the study.

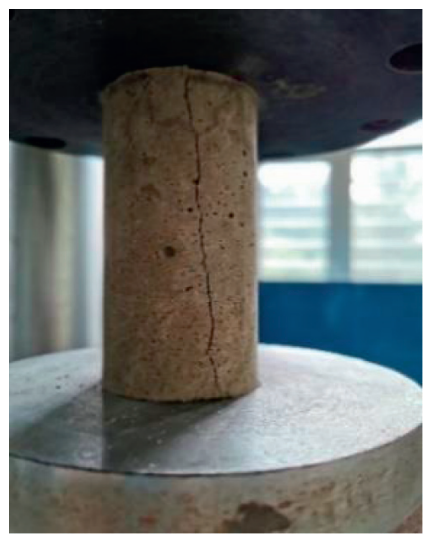

(a)

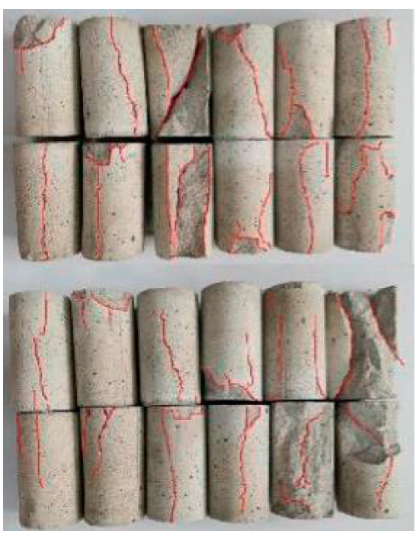

(b)

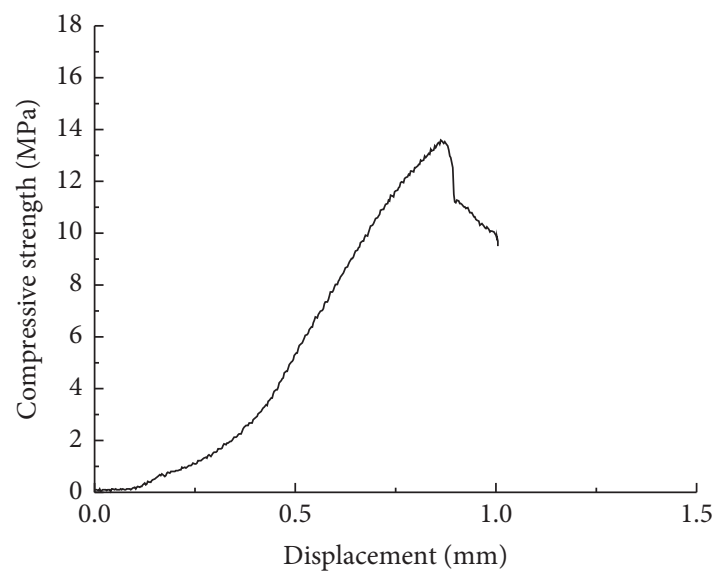

(c)

Figure 5: Compressive strength test of similar materials covered by the study. (a) Uniaxial compression test. (b) Failure of specimens. (c) Stress-displacement curve of the fifth group of specimens from the compressive test.

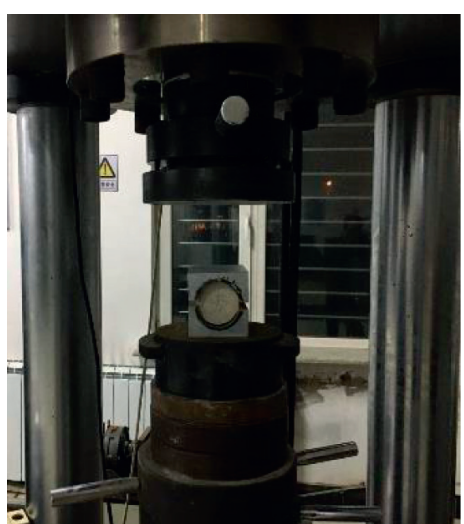

(a)

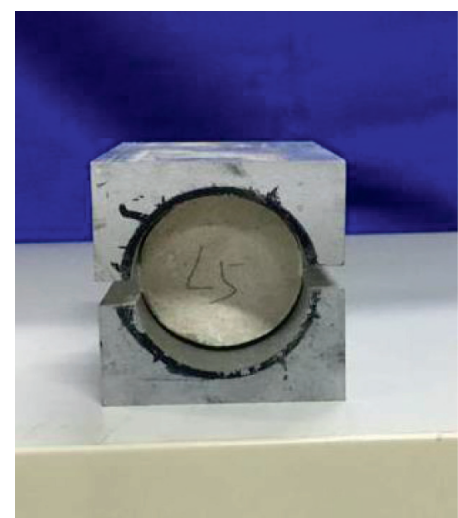

(b)

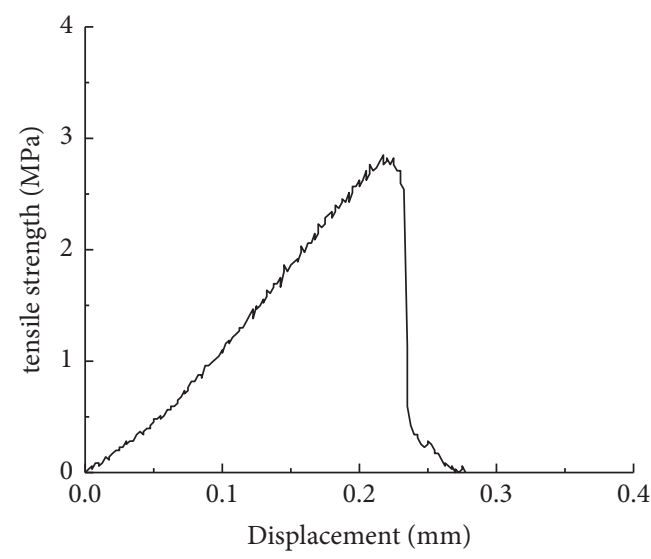

L5

Figure 6: Tensile strength test of similar materials covered by the study. (a) Tensile strength test. (b) Tensile strength test specimen. (c) Stress-displacement curve of the fifth group of specimens from the tensile test. 
TABLE 4: Test results of orthogonal ratio covered by the study.

\begin{tabular}{|c|c|c|c|c|}
\hline $\begin{array}{l}\text { Group } \\
\text { number }\end{array}$ & Compressive strength $\left(\sigma_{c} / \mathrm{MPa}\right)$ & Tensile strength $\left(\sigma_{t} / \mathrm{MPa}\right)$ & Elastic modulus $(E / G P a)$ & $\begin{array}{l}\text { Ratio of compressive to tensile strength } \\
\qquad\left(\sigma_{c} / \sigma_{t}\right)\end{array}$ \\
\hline L1 & 14.14 & 2.73 & 2.03 & 5.18 \\
\hline $\mathrm{L} 2$ & 13.00 & 2.76 & 1.81 & 4.71 \\
\hline L3 & 13.50 & 2.47 & 1.57 & 5.46 \\
\hline $\mathrm{L} 4$ & 9.94 & 2.09 & 2.86 & 4.76 \\
\hline L5 & 13.59 & 2.85 & 2.16 & 4.77 \\
\hline L6 & 8.83 & 2.33 & 2.23 & 3.79 \\
\hline L7 & 12.15 & 2.44 & 1.65 & 4.98 \\
\hline L8 & 11.50 & 2.37 & 1.74 & 4.85 \\
\hline L9 & 12.47 & 2.23 & 2.07 & 5.59 \\
\hline L10 & 12.88 & 2.48 & 1.72 & 5.19 \\
\hline L11 & 10.93 & 2.62 & 1.96 & 4.17 \\
\hline L12 & 9.30 & 2.12 & 1.53 & 4.39 \\
\hline L13 & 13.29 & 2.24 & 1.82 & 5.93 \\
\hline L14 & 9.94 & 2.82 & 1.84 & 3.52 \\
\hline L15 & 9.79 & 2.16 & 1.76 & 4.53 \\
\hline L16 & 8.96 & 2.01 & 1.96 & 4.46 \\
\hline
\end{tabular}

values of the test results for each influencing factor. The specific calculation method is shown in

$$
\begin{aligned}
& I_{i}=\frac{X_{1}+X_{2}+\cdots \cdots+X_{i}}{i}, \\
& R=I_{\max }-I_{\min },
\end{aligned}
$$

where $I_{i}$ is the average value of the test results of each influencing factor, $X_{i}$ is the $i$-th test result of the influencing factor, $R$ is the range, $I_{\max }$ is the maximum average value, and $I_{\min }$ is the minimum average value of the test results of each influencing factor.

In terms of the performance of the numerical value, the range can directly reflect the influence of different levels of this factor on the index. A large range is interpreted as follows: the greater the range, the more obvious the influence of this factor on the test results. The following is an analysis of the influence of each factor on the physical and mechanical properties of the similar materials of white sandstone.

3.1. Analysis of Factors Affecting Compressive Strength. The relationship between the compressive strength of the similar material specimens and the levels of the four listed factors is shown in Figure 7. The abscissa represents the different levels of quartz sand content, iron powder content, gypsum-cement ratio, and sand particle size, and the ordinate represents the compressive strength of the specimens of similar materials.

As shown in Figure 7, as the quartz sand content increases, the uniaxial compressive strength of the similar material model of white sandstone has a decreasing trend. This is due to insufficient bonding between the sand particles of similar materials, which reduces the compressive strength $\sigma_{c}$ of the material model. The relationship between the compressive strength $\sigma_{c}$ of the similar materials and the iron powder content first decreases, then increases, and then decreases again. The main reason for this trend is that the iron powder has a certain strength. Because of the difference between the molecules' contact, the sand grains in the specimen are not in good contact, resulting in a decrease in the density. When the added iron powder completely fills the pores between the sand grains, the compressive strength $\sigma_{c}$ will increase. Excessive iron powder content will reduce the density of the test piece, resulting in a decrease in its compressive strength. As the ratio of gypsum to cement increases, the compressive strength $\sigma_{c}$ of the similar material model gradually increases. The influence of the particle size of the sand in the test block on the compressive strength $\sigma_{c}$ is as follows: with an increase in the sand particle size, the compressive strength $\sigma_{c}$ increases first and then decreases. The compressive strength $\sigma_{c}$ reaches the maximum when the sand particle size is $1-2 \mathrm{~mm}$. This is because as the particle size of the sand increases, the contact area and friction between the sand particles increases, resulting in increased compressive strength of the specimens of similar materials. However, with continuous increase in the sand particle size, the contact area between the sand particles no longer increases, but the internal pores of the specimens of the similar materials become larger; the contact between the particles becomes unstable, and the low density of the specimens causes the similar materials to be compressed. There was a downward trend in the density. The maximum value of the compressive tensile ratio is mainly due to the proper combination of gypsum, water, and sand when the sand particle size is $1-2 \mathrm{~mm}$. Therefore, the compactness of the specimen is ensured, and due to the action of gypsum and the curing time, the brittleness of the specimen is obvious, which is manifested by the larger value of the compressive tensile ratio.

The results of the compressive strength $\sigma_{c}$ in the orthogonal test are presented in Table 5 .

In the table, $I_{\mathrm{i}}(i=1,2,3,4)$ represents the average value of the corresponding compressive strength $\sigma_{c}$ at level $i$. It can be seen from Table 5 that the iron powder content has the greatest influence on the test results. Based on this, it can be concluded that the compressive strength $\sigma_{c}$ of the similar material model is affected by the various factors in the order $A>D>B>C$. 


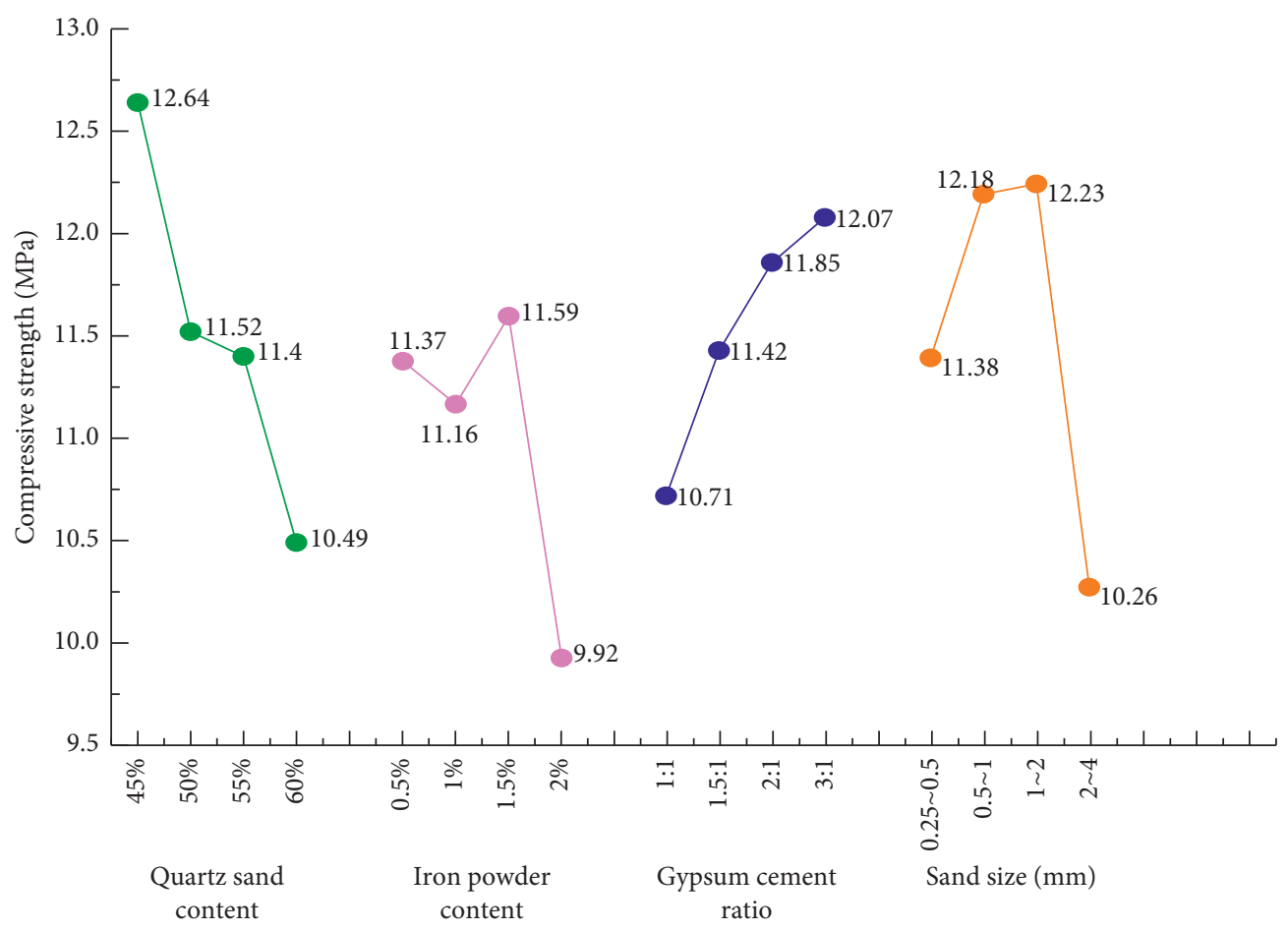

FIGURE 7: Influence of various factors on compressive strength of similar materials covered by the study.

TABLE 5: Analysis of the extreme difference in compressive strength of each factor covered by the study.

\begin{tabular}{lcccc}
\hline Factor level & (A) Quartz sand (\%) & (B) Iron powder (\%) & (C) Plaster : cement & (D) Sand size (mm) \\
\hline $\mathrm{I}_{1}$ & 12.64 & 11.37 & 10.71 & 11.38 \\
$\mathrm{I}_{2}$ & 11.52 & 11.16 & 11.42 & 12.18 \\
$\mathrm{I}_{3}$ & 11.40 & 11.59 & 11.85 & 12.23 \\
$\mathrm{I}_{4}$ & 10.49 & 9.92 & 12.07 & 10.26 \\
Range & 2.15 & 1.67 & 1.35 & 1.98 \\
\hline
\end{tabular}

3.2. Analysis of Factors Affecting Tensile Strength. As shown in Figure 8, the analysis of the tensile strength $\sigma_{t}$ of the similar materials reveals that, with an increase in the quartz sand content, the tensile strength $\sigma_{t}$ of the white sandstone similar material model gradually decreases. This is mainly attributed to the increase in quartz sand content, decrease in the cementing material in the model, increase in the voids in the specimen, and insufficient bonding between the sand particles. At the same time, the influence of iron powder content on the tensile strength $\sigma_{t}$ is described as follows: with an increase in the iron powder content, the tensile strength $\sigma_{t}$ of the similar materials first increases and then decreases. The main reason for this phenomenon is that an appropriate amount of iron powder filling the gaps between the sand grains makes the similar material model compact and increases the tensile strength $\sigma_{t}$. At the same time, excessive iron powder causes the sand grains to separate, and the friction between the sand grains is reduced, resulting in a decrease in the tensile strength. As the ratio of gypsum to cement increases, the tensile strength of the model first increases and then decreases. This is because when gypsum is added to the cement, the tensile strength $\sigma_{t}$ of the similar materials increases. When the gypsum content is greater than the cement content, the tensile strength $\sigma_{t}$ will decrease because the tensile strength $\sigma_{t}$ of gypsum is lower than that of cement, which leads to a decrease in the overall tensile strength $\sigma_{t}$ of the similar material model. The tensile strength $\sigma_{t}$ is the largest when the iron powder content is $1 \%$, and the gypsum-cement ratio is $1.5: 1$. The tensile strength $\sigma_{t}$ of the similar material model decreases with an increase in the sand particle size. This is because the internal voids of the similar material model increase as the particle size of the sand increases, and the density of the model decreases, resulting in a decrease in the tensile strength $\sigma_{t}$.

The results of the tensile strength $\sigma_{t}$ from the orthogonal test are shown in Table 6.

It can be seen from Table 6 that the iron powder content has the greatest influence on the tensile strength of the similar material model. In summary, the order of influence of the various factors on the tensile strength $\sigma_{t}$ of the white sandstone similar material is $B>D>A>C$.

3.3. Analysis of Influencing Factors of Elastic Modulus. As shown in Figure 9, with an increase in the contents of quartz sand and iron powder, the elastic modulus $E$ shows an initial decreasing trend followed by an increasing trend. When the quartz sand content reaches 55\% and the iron powder 


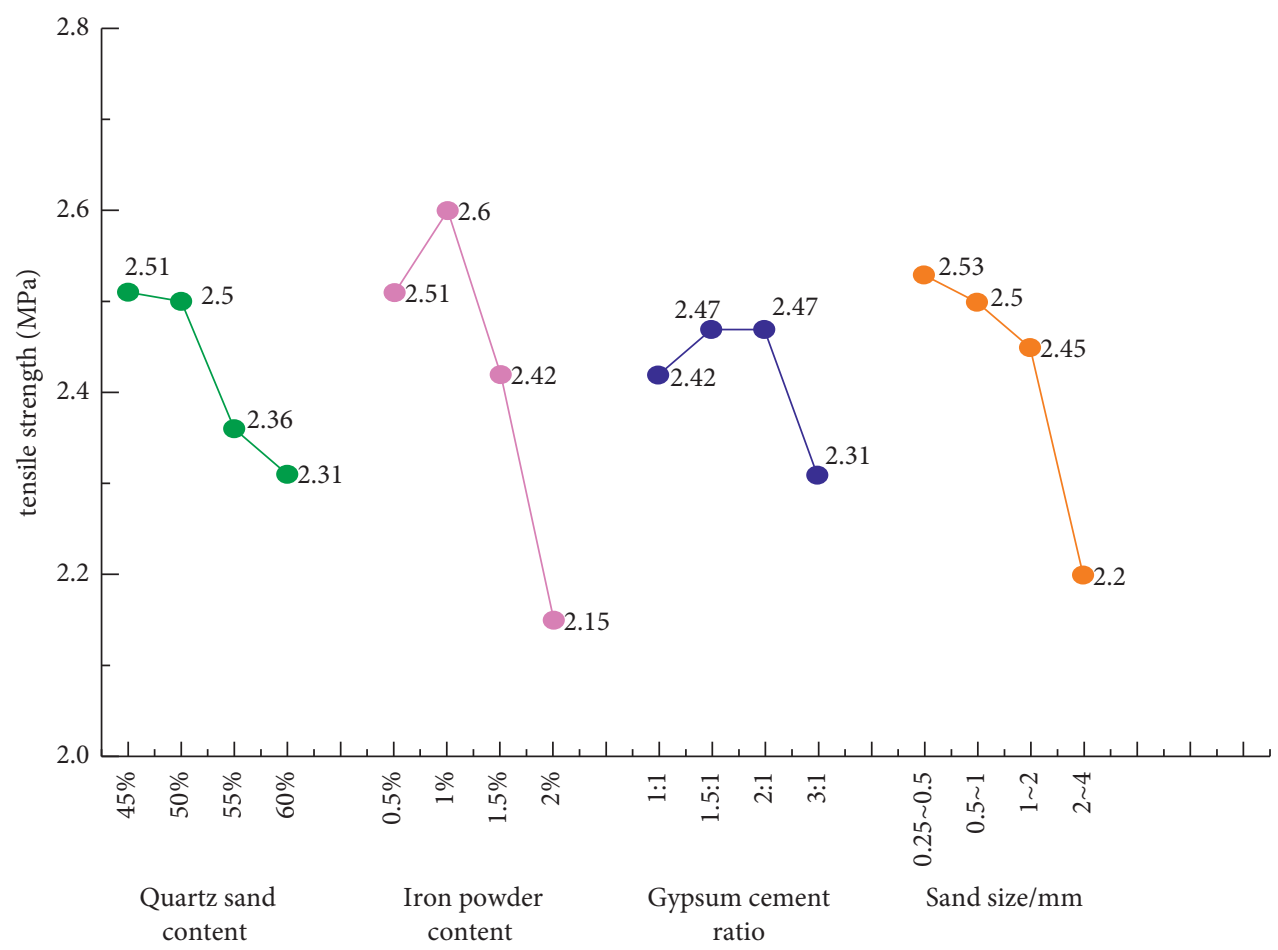

FIGURE 8: Influence of various factors on tensile strength of similar materials covered by the study.

TABLe 6: Analysis of the extreme difference in tensile strength of various factors covered by the study.

\begin{tabular}{lcccc}
\hline Factor level & (A) Quartz sand (\%) & (B) Iron powder (\%) & (C) Plaster : cement & (D) Sand size (mm) \\
\hline $\mathrm{I}_{1}$ & 2.51 & 2.51 & 2.42 & 2.53 \\
$\mathrm{I}_{2}$ & 2.50 & 2.60 & 2.47 & 2.50 \\
$\mathrm{I}_{3}$ & 2.36 & 2.42 & 2.47 & 2.45 \\
$\mathrm{I}_{4}$ & 2.31 & 2.15 & 2.31 & 2.20 \\
Range & 0.21 & 0.45 & 0.16 & 0.33 \\
\hline
\end{tabular}

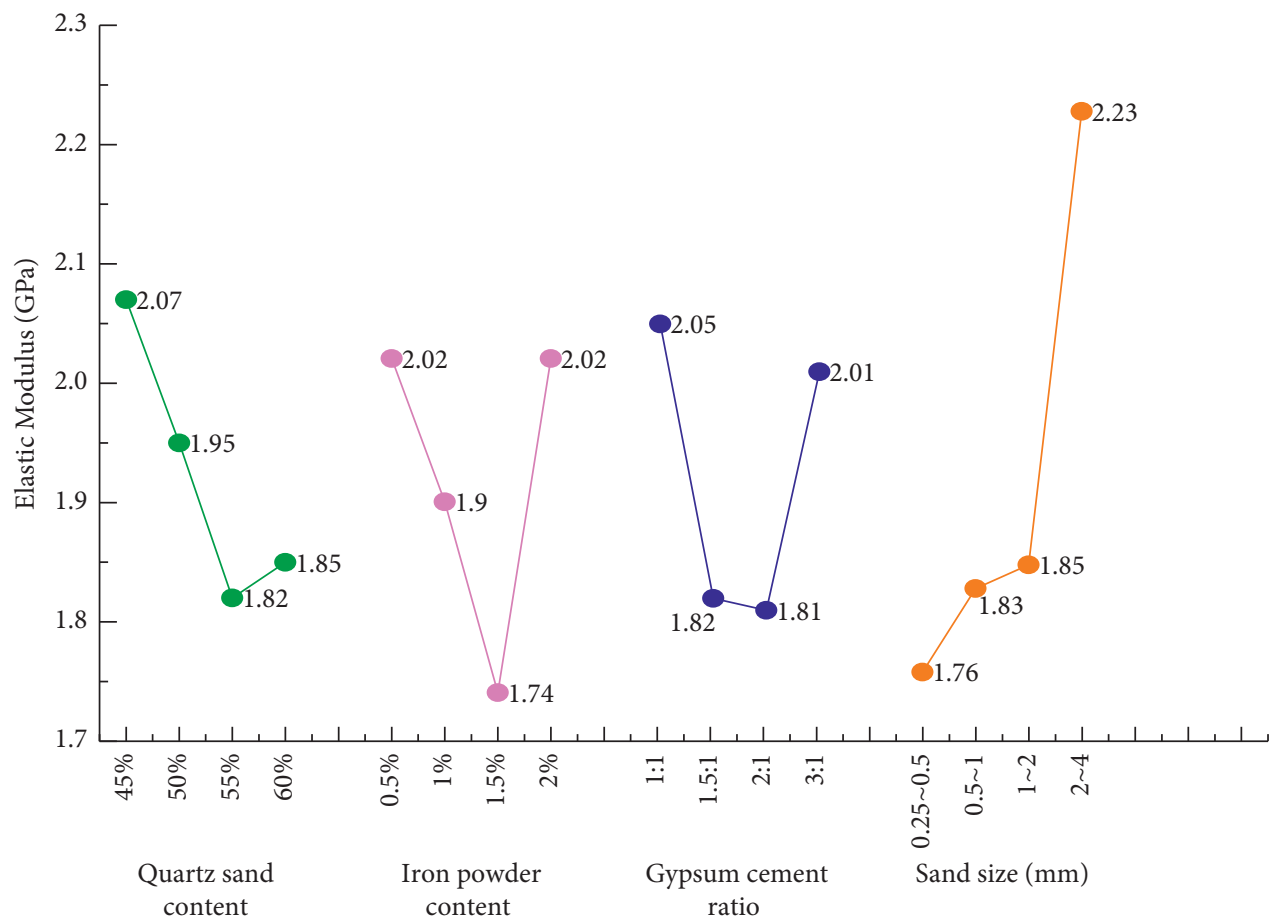

Figure 9: Influence of various factors on the elastic modulus of similar materials covered by the study. 
content reaches $1.5 \%$, the performance of similar materials with regard to the elastic modulus $E$ reaches the minimum. There are numerous microcracks in the rock under pressure. The low elastic modulus indicates that the cementing ability between two molecules decreases, which makes the rock more brittle. As the ratio of gypsum to cement increases in the similar material model, the elastic modulus $E$ decreases first and then increases. When the ratio of gypsum to cement is $2: 1$, the elastic modulus of the model is the smallest. The elastic modulus $E$ of the similar material model shows a continuous increase with an increase in the sand particle size. The higher elastic modulus at this time indicates that as the sand particle size increases, the expansion of internal cracks in the rock mass is inhibited, and the fracture energy of the rock mass under pressure is reduced. Macroscopically, the brittleness characteristics of the rock are not obvious when the rock fractures.

The results of the elastic modulus $E$ from the orthogonal experiment are presented in Table 7.

It can be seen from Table 7 that the sand particle size has the greatest influence on the elastic modulus of the similar material model. In summary, the order of the degree of influence of various factors on the elastic modulus of white sandstone similar materials is $D>B>A>C$.

\subsection{Analysis of Influencing Factors of Compressive and Tensile} Ratios. The brittleness coefficient refers to the ratio of the compressive strength to tensile strength of the test piece; it is a physical quantity that reflects the brittleness of the rock. The influence of various factors on the compression and tensile ratios of the similar materials is shown in Figure 10.

As shown in Figure 10, the trends of the influence of quartz sand content and iron powder content on the compressive tensile ratio of the similar material model first decreases, then increases, and again decreases. The main reason for this is that the compaction of the similar material specimens is affected by iron powder and quartz sand. The common influence on the similar materials accelerates the expansion of the internal cracks of the model under the action of the load. The compressive tensile ratio of the similar materials increases with an increase in the gypsum-cement ratio. The particle size of sand influences the compressive resistance of the similar materials; the trend shows an initial increase followed by a decrease. When the sand particle size is 1-2 $\mathrm{mm}$, the compressive and tensile ratios of the similar materials reach the maximum. The compressive tensile ratio of the model represents the brittleness characteristics of the rock. The larger the compressive tensile ratio, the more imbalanced the internal stress of the similar material model and the greater the brittleness index of the rock. This promotes the development of internal cracks caused by rock expansion and extension under loading.

The extreme differences in the compressive and tensile ratios in the orthogonal test are shown in Table 8 .

It can be seen from the table that the largest range is in column $D$. It can be concluded that the compressive and tensile ratios of similar materials are affected in the order of $D>B>A>C$.
3.5. Comparative Analysis of Failure Modes of Rockburst Similar Materials and Original Rock. A comparative analysis of the failure modes of rockburst similar materials and the original rock was performed at the macrolevel. The failure form of a part of the specimen is shown in Figure 3(b). The final failure modes of the rockburst similar materials and white sandstone are summarised as follows: tensile failure occurs in a small number of rock specimens; the tension failure surface is dominated by a single tension surface, and the failure form is similar to that of the original white sandstone rock under uniaxial compression; the number of rock specimens dominated by shear failure is equivalent to that of tension failure. Shear failure mainly appears as one or more clearly visible cracks along the diagonal direction, with obvious failure surfaces. In addition to the main shear surface, there are a large number of local failure surfaces caused by the low tensile strength of a small number of specimens. Tensile and shear composite failures were observed in the vast majority of specimens and were manifested as lamellar spalling on the sides of both ends of the specimens. Numerous cracks were observed in the axial direction, and the overall failure of the specimens was caused by two or more interconnected shear planes occurring together.

Table 9 shows the performance comparison of rockburst similar materials and the failure modes of the original rock.

\section{Optimal Ratio of Similar Materials}

4.1. Fitting of Mechanical Parameters of Similar Materials. Referring to the test results in Table 4, the four parameters of quartz sand content, iron powder content, gypsum-cement ratio, and sand particle size are considered as independent variables and compressive strength, tensile strength, compressive tensile ratio, and elastic modulus as dependent variables. Then, the relationship between an independent variable and dependent variable is fitted with Origin software to establish a multiple linear regression equation, as shown as follows:

$$
\begin{aligned}
\sigma_{c}= & 20.47191-13.15295 x_{1}-198.1285 x_{2} \\
& +0.64007 x_{3}-0.41513 x_{4}, \\
\sigma_{t}= & 3.81755-1.5 x_{1}-25.4 x_{2}-0.06229 x_{3}-0.09374 x_{4}, \\
E= & 2.52789-1.585 x_{1}-3.15 x_{2}+0.009 x_{3}+0.13126 x_{4}, \\
\frac{\sigma_{c}}{\sigma_{t}}= & 5.495-2.0222 x_{1}-35.0552 x_{2} \\
& +0.41225 x_{3}+0.00348 x_{4},
\end{aligned}
$$

where $\sigma_{c}$ is the compressive strength $(\mathrm{MPa}), \sigma_{t}$ is the tensile strength $(\mathrm{MPa}), E$ is the modulus of elasticity $(\mathrm{GPa}), \sigma_{c} / \sigma_{t}$ is the tension-compression ratio, $x_{1}$ is the quartz sand content, $x_{2}$ is the iron powder content, $x_{3}$ is the gypsum-cement ratio, and $x_{4}$ is the sand particle size. 


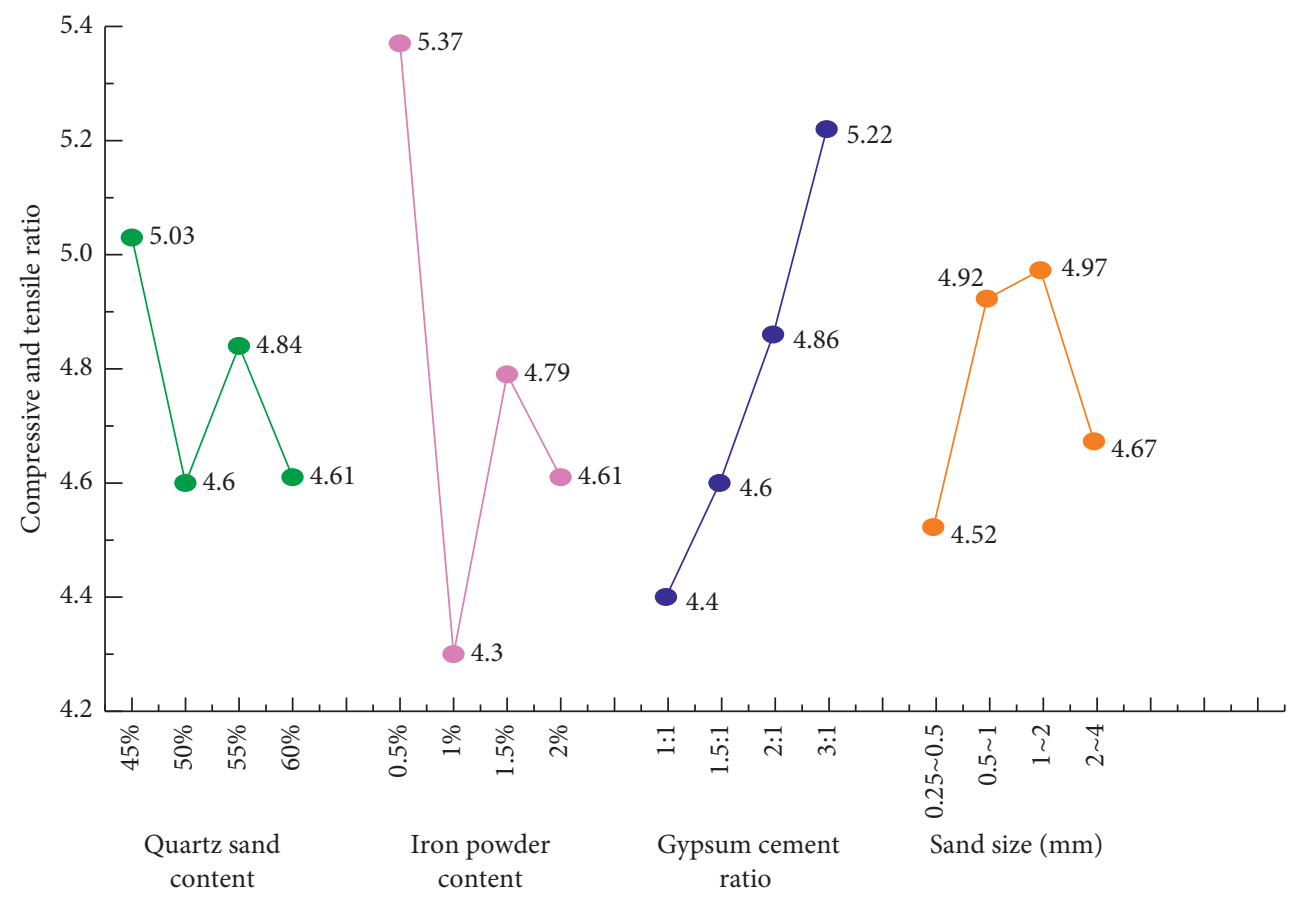

FIGURE 10: Influence of various factors on the compressive and tensile strengths of similar materials covered by the study.

TABLE 7: Analysis of the difference in elastic modulus of each factor covered by the study.

\begin{tabular}{lcccc}
\hline Factor level & (A) Quartz sand (\%) & (B) Iron powder (\%) & (C) Plaster : cement & (D) Sand size (mm) \\
\hline $\mathrm{I}_{1}$ & 2.07 & 2.02 & 2.05 & 2.53 \\
$\mathrm{I}_{2}$ & 1.95 & 1.90 & 1.82 & 2.50 \\
$\mathrm{I}_{3}$ & 1.82 & 1.74 & 1.81 & 2.45 \\
$\mathrm{I}_{4}$ & 1.85 & 2.02 & 2.01 & 2.20 \\
Range & 0.25 & 0.29 & 0.24 & 0.33 \\
\hline
\end{tabular}

TABLE 8: Analysis of the compression and tensile ratios' range of different factors under compression covered by the study.

\begin{tabular}{lcccc}
\hline Factor level & (A) Quartz sand (\%) & (B) Iron powder (\%) & (C) Plaster : cement & $(\mathrm{D})$ Sand size $(\mathrm{mm})$ \\
\hline $\mathrm{I}_{1}$ & 2.07 & 2.02 & 2.05 & 1.76 \\
$\mathrm{I}_{2}$ & 1.95 & 1.90 & 1.82 & 1.83 \\
$\mathrm{I}_{3}$ & 1.82 & 1.74 & 2.81 & 1.85 \\
$\mathrm{I}_{4}$ & 1.85 & 2.02 & 0.01 & 2.23 \\
Range & 0.25 & 0.29 & 0.24 & 0.47 \\
\hline
\end{tabular}

TABLE 9: Comparison of failure modes between rockburst similar materials and white sandstone covered by the study. The failure modes of rockburst similar materials and original rock can be divided into tension failure, shear failure, tension, and shear failure.

\begin{tabular}{lll}
\hline Form of destruction & Tension destruction & Tension and shear combined failure \\
Destruction model &
\end{tabular}


TABle 9: Continued.

\begin{tabular}{llll}
\hline Form of destruction & Tension destruction & Tension and shear combined failure \\
Rockburst similar materials & Shear failure & & \\
Raw rock & &
\end{tabular}

4.2. Determination of the Optimal Ratio of Similar Materials. The main criteria for selecting similar materials are as follows [1]:

$$
\begin{aligned}
\alpha & =\frac{l_{m}}{l_{P}}, \\
\beta & =\frac{\gamma_{M}}{\gamma_{P}}, \\
\sigma_{c}^{M} & =\sigma_{c} \alpha \beta, \\
E^{M} & =E \alpha \beta, \\
\sigma_{t}^{M} & =\sigma_{t} \alpha \beta, \\
\mu^{M} & =\mu,
\end{aligned}
$$

where $l_{p}$ is the original rock size $(\mathrm{mm}), l_{m}$ is the size of the similar model specimens $(\mathrm{mm}), \alpha$ is the geometric similarity coefficient, $\beta$ is the gravity similarity coefficient, $\gamma_{P}$ is the natural gravity of white sandstone $\left(\mathrm{kN} / \mathrm{m}^{3}\right), \gamma_{M}$ is the dry weight of the similar material model $\left(\mathrm{kN} / \mathrm{m}^{3}\right), \sigma_{c}$ is the uniaxial compressive strength of the original rock $(\mathrm{MPa}), \sigma_{c}^{M}$ is the uniaxial compressive strength of the similar material model $(\mathrm{MPa}), E$ is the elastic modulus of the original rock $(\mathrm{GPa}), E^{M}$ is the elastic modulus of the similar material model (GPa), $\mu$ is Poisson's ratio of the original rock, and $\mu^{M}$ is Poisson's ratio of the similar material model.

The mechanical parameters of the specimens of similar materials are calculated according to the physical and mechanical parameters of the original rock in Table 1 and the standard formula for the selection of similar materials, and the results are presented in Table 10 .

The optimal ratio of the similar materials calculated by the multiple linear regression equation obtained by fitting in Section 3.1 is shown in Table 11.
The optimal ratio was determined at room temperature $\left(25^{\circ} \mathrm{C}\right)$. This optimal ratio is affected by temperature, which is specifically manifested under the incorporation of iron powder, which has a strong influence on thermal conductivity. The more the quantity of iron powder added, the greater the influence on the temperature of the specimen and the greater the sensitivity of the specimen to heat. Secondly, the thermal expansion coefficients of rock and minerals are different at high temperature, and the deformations of various mineral particles in the rock are different after the rock is heated. In addition, the porosity of the specimen changes with temperature owing to the thermal expansion of the framework. The change in temperature causes changes in the distance between the particles in the specimen. In addition, under certain temperature conditions, the internal physical properties of the specimen will change, producing thermal stress in the rock specimen. Moreover, the mineral structure and composition change when the temperature changes.

\subsection{Judgement of Rockburst Tendency of Similar Materials.} White sandstone has obvious brittleness characteristics and exhibits a strong rockburst tendency. To determine whether the similar materials have the same rockburst tendency as the original white sandstone rock, the rockburst tendency of the similar material specimens was analysed, and the resistance deduced from the compressive tensile ratio and stress-strain curve was used to verify the rockburst tendency of the similar materials [18].

(1) The ratio of the tensile and compressive strengths indicates the rockburst tendency of the similar materials [23]. It is a commonly used method to judge the rockburst tendency based on the brittleness characteristics of rocks. The general basis for judgement is as follows: 
TABLE 10: Mechanical parameters of similar materials covered by the study.

\begin{tabular}{lccc}
\hline Material & Compressive strength $\left(\sigma_{c} / \mathrm{MPa}\right)$ & Tensile strength $\left(\sigma_{t} / \mathrm{MPa}\right)$ & Elastic modulus $(E / \mathrm{GPa})$ \\
\hline Similar material & 11.50 & 2.37 & 2.86 \\
\hline
\end{tabular}

TABLE 11: Optimal ratio of similar materials obtained by multiple linear regression covered by the study.

\begin{tabular}{lcccc}
\hline Similar material & (A) Quartz sand (\%) & (B) Iron powder (\%) & (C) Plaster : cement & (D) Sand size (mm) \\
\hline White sandstone & 36 & 1.9 & $1.8: 1$ & $2-4$ \\
\hline
\end{tabular}

When $\sigma_{c} / \sigma_{t} \leq 14.5$, the material exhibits a strong rockburst tendency; when $14.5<\sigma_{c} / \sigma_{t} \leq 26.7$, the material has a moderate rockburst tendency; when $26.7<$ $\sigma_{c} / \sigma_{t} \leq 40$, the material has a weak rockburst tendency; when $\sigma_{c} / \sigma_{t}>40$, there is no rockburst tendency.

(2) The rockburst tendency of the similar materials based on the ratio of the envelope area of the stressstrain curve before and after the peak is shown in equation (6) [5]:

$$
W_{c f}=\frac{F_{1}}{F_{2}}
$$

where $F_{1}$ is the area before the peak and $F_{2}$ is the area after the peak. When $W_{c f}>3.0$, the material exhibits a strong rockburst tendency; when $2.0<W_{c f} \leq 3.0$, the material exhibits a moderate rockburst tendency; when $1.0 \leq W_{c f} \leq$ 2.0, the material exhibits a weak rockburst tendency; when $W_{c f}<1.0$, no rockburst tendency is observed.

See Table 12 for the judgement of the rockburst tendency of the similar materials.

The verification of the rockburst tendency index shows that the specimens of similar materials have a strong rockburst tendency, and the similar materials can better simulate the characteristics of white sandstone, which is an ideal rockburst similar material.

\section{Analysis of the Influence of Temperature on Similar Materials of Rockburst}

To further study the occurrence mechanism of rockburst and predict rockburst in the future, the optimal ratio was selected in this experiment and five sets of specimens were prepared. Uniaxial compression tests and tensile tests were performed on rockburst similar materials after different temperature treatments to macroscopically define the failure forms of the rockburst materials at different temperatures, investigate the related reasons, and further explore the generation of failure through changes in energy and degree of damage to the rock during a rockburst. In order to study the influence of temperature as the only variable on rockburst similar materials, the optimal content of iron powder is kept unchanged, and the influence changes of materials at different temperatures are analysed. Figure 11 shows the heating of specimens. Figure 12 shows the uniaxial compression test of similar materials at different temperatures.

The uniaxial compressive strength curves of the rockburst similar materials at different temperatures are shown in Figure 13.
TABLE 12: Judgement of rockburst tendency of similar materials covered by the study.

\begin{tabular}{lcc}
\hline Group number & $\sigma_{\mathrm{c}} / \sigma_{\mathrm{t}}$ & $W_{c f}$ \\
\hline 1 & 5.18 & 4.52 \\
2 & 4.71 & 5.03 \\
3 & 5.46 & 6.14 \\
4 & 4.76 & 3.98 \\
5 & 4.77 & 5.72 \\
6 & 3.79 & 4.57 \\
7 & 4.98 & 3.48 \\
8 & 4.85 & 5.15 \\
9 & 5.59 & 5.26 \\
10 & 5.19 & 3.45 \\
11 & 4.17 & 5.13 \\
12 & 4.39 & 3.96 \\
13 & 5.93 & 2.70 \\
14 & 3.52 & 7.02 \\
15 & 4.53 & 3.95 \\
16 & 4.46 & 5.09 \\
\hline
\end{tabular}

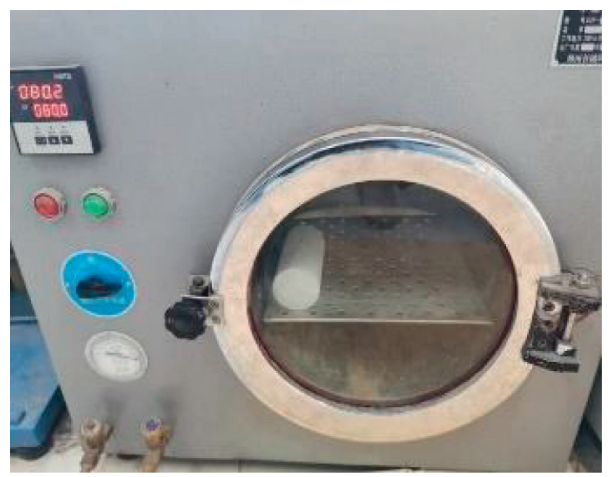

FIGURE 11: Heating of specimens covered by the study.

The stress-strain curves of rockburst similar materials under different temperature conditions can be divided into four stages. The first stage is the initial compaction stage, in which the microcracks inside the specimen are closed. The second stage is the elastic deformation stage, wherein an external force is applied to the specimen, and the consequent deformation can be restored by removing the external force. This stage represents the energy accumulation stage, where the particles in the rock body are displaced to generate potential energy. When the external force is removed, the particles can be restored to their original positions, and the potential energy can be released. This is the formation stage of the microcracks. The third stage is the plastic deformation stage. The slope of 


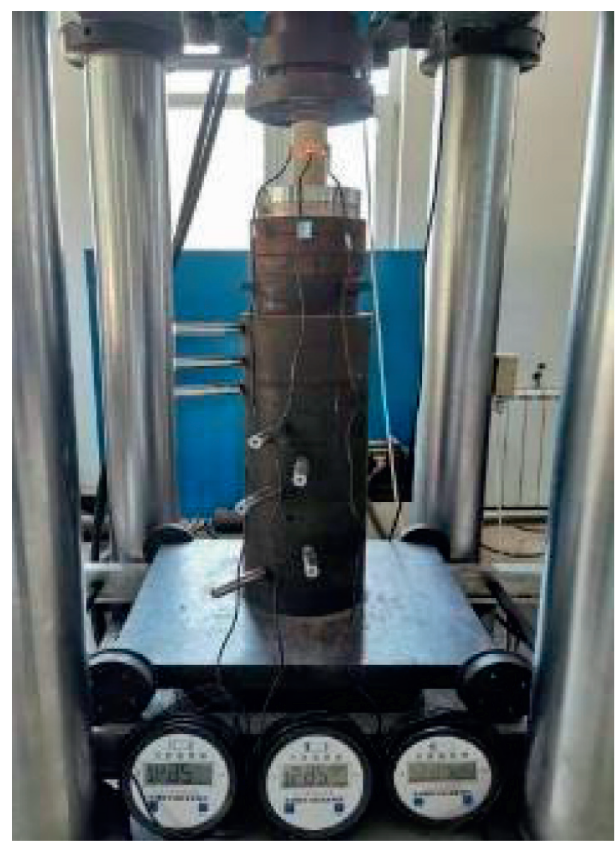

(a)

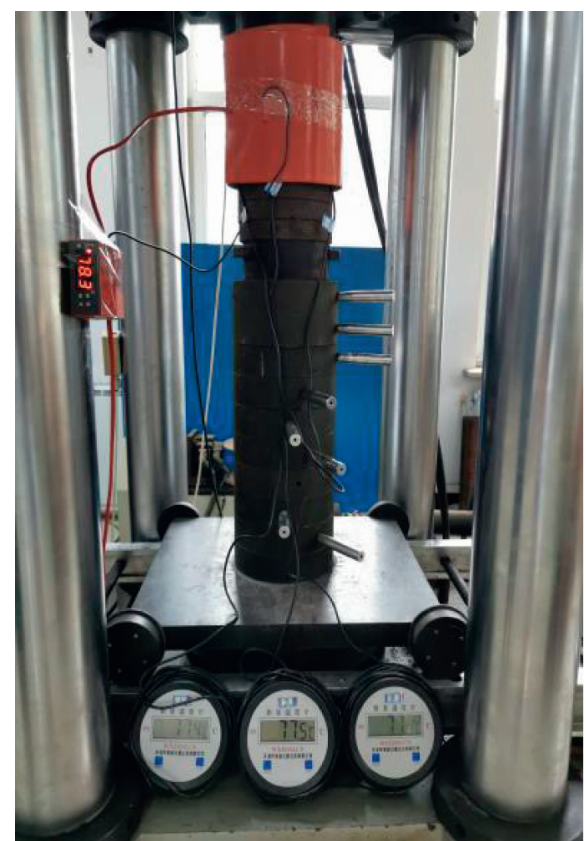

(b)

Figure 12: Uniaxial compression test of similar materials at different temperatures covered by the study.

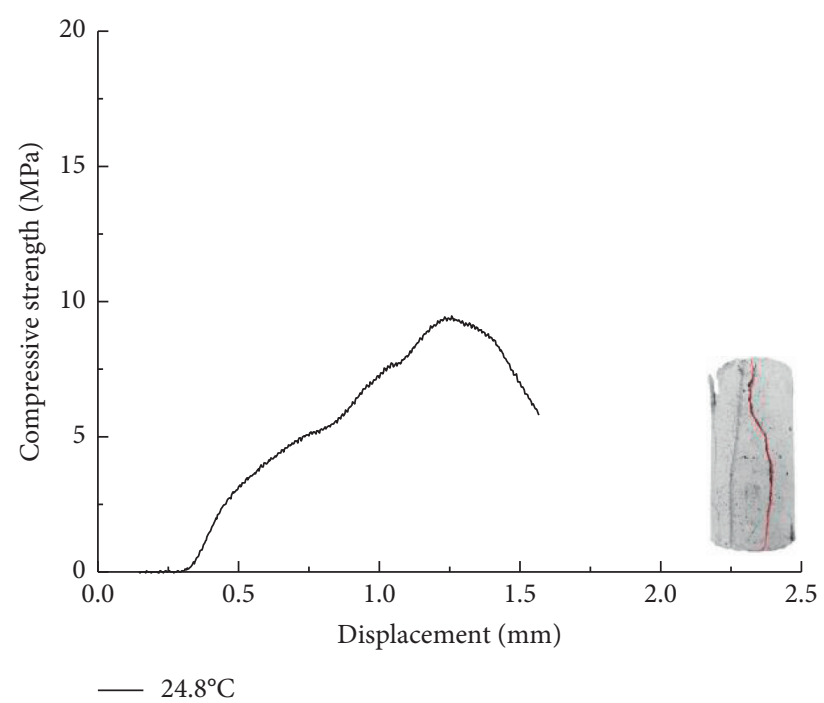

(a)

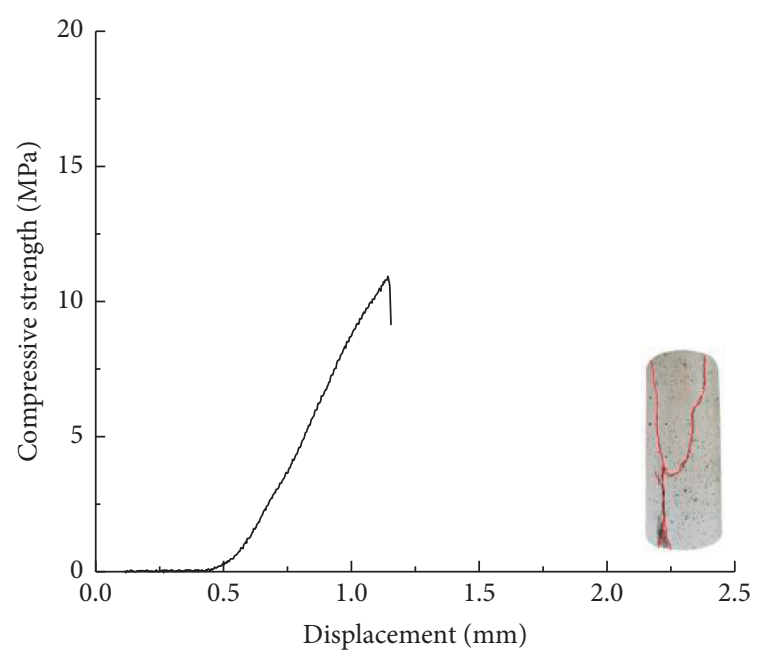

(b)

Figure 13: Continued. 


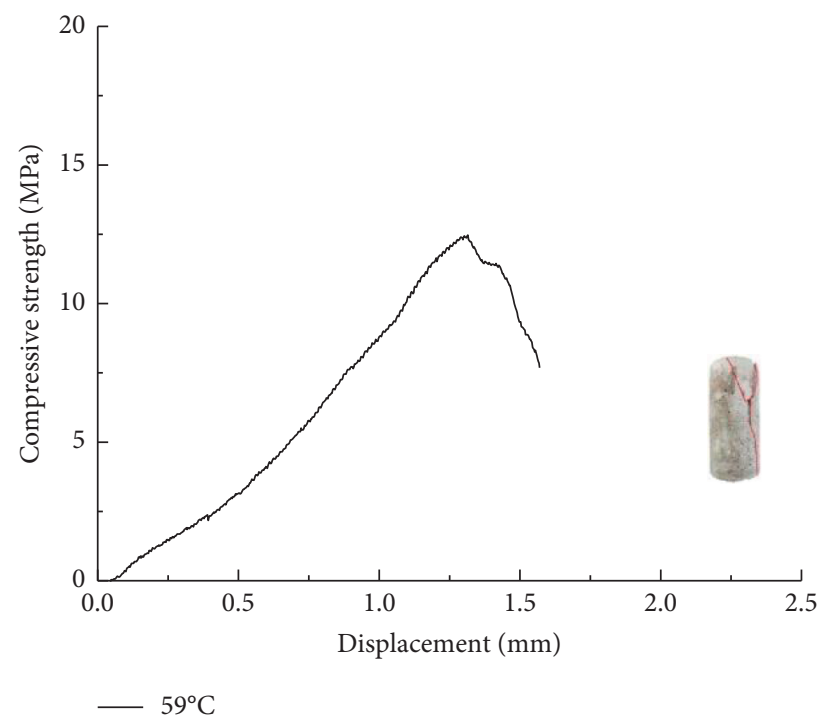

(c)

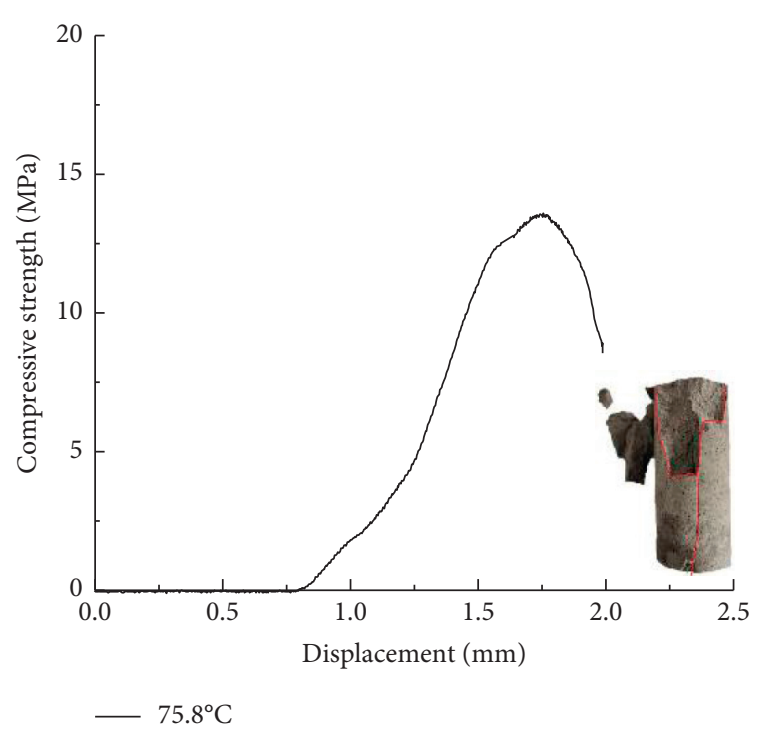

(d)

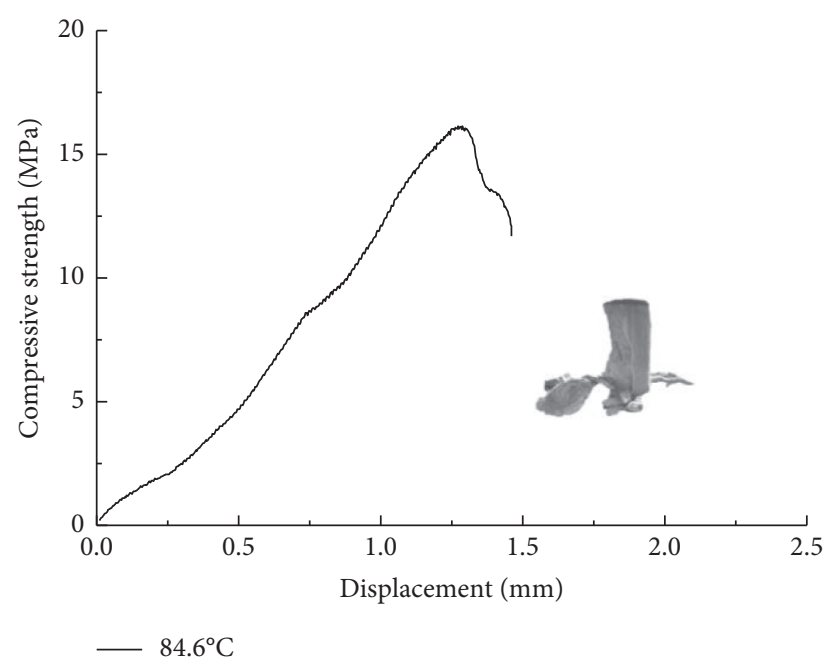

(e)

FiguRE 13: Uniaxial compressive strength curves of the rockburst similar materials at different temperatures covered by the study.

the stress-strain curve at this stage gradually decreases. The slopes of the concave curves of the rockburst similar materials under different temperature conditions are different, but the slope of the curve is zero when the stress is at its peak. Owing to the brittleness of the rockburst similar materials, the plastic deformation of the specimen is extremely small. At this stage, microcracks continue to form and expand. The fourth stage is the destruction stage. At this stage, the stress-strain curve drops rapidly, and the slope of the curve becomes negative. The crack extends and penetrates through the rock, the elastic strain energy in the rock body is released, and the specimen is finally destroyed.

From the macroscopic fracture pattern of rockburst similar materials, it can be seen that as the temperature increases, the degree of rockburst similar materials fracture increases, and the anisotropy is obvious.
Below $24.8^{\circ} \mathrm{C}$, the rock composition is stable and the distribution is relatively uniform. The broken form of rockburst similar materials will break along the main weak structural planes, mainly oriented intercrystal pores. At room temperature, the microscopic defects of rockburst similar materials are mainly micropores, and their distribution is uneven.

At $24.8-42.3^{\circ} \mathrm{C}$, the structure of rockburst similar materials is tight, pores and cracks are not developed, the contact state between mineral particles is good, the surface of the fracture is uneven, various pits of different shapes can be seen on the surface of the fracture, and the microcracks are not developed. Microcracks expand along the edges of the particles, and pores appear on the surface of the mineral particles, which will undergo thermal oxidation and decomposition under a certain temperature, and gas will escape from the rockburst similar materials, creating voids in the rockburst similar materials. 
TABLE 13: Mechanical properties of similar materials at different temperatures covered by the study.

\begin{tabular}{lcccc}
\hline Temperature $\left({ }^{\circ} \mathrm{C}\right)$ & $\begin{array}{c}\text { Compressive strength } \\
\left(\sigma_{c} / \mathrm{MPa}\right)\end{array}$ & Tensile strength $\left(\sigma_{t} / \mathrm{MPa}\right)$ & Compressive to tensile strength ratio $\left(\sigma_{c} / \sigma_{t}\right)$ & Energy $\left(\mathrm{MJ} / \mathrm{m}^{3}\right)$ \\
\hline 24.8 & 9.47 & 1.57 & 6.02 & 5.03 \\
42.3 & 10.93 & 1.78 & 6.14 & 5.24 \\
59 & 12.47 & 1.98 & 6.3 & 6.14 \\
75.8 & 13.59 & 2.13 & 6.39 & 6.82 \\
84.5 & 16.14 & 2.50 & 6.46 & 7.43 \\
\hline
\end{tabular}

At $42.3^{\circ} \mathrm{C}-75.8^{\circ} \mathrm{C}$, with the occurrence of dehydration, the composition of the mineral changes, the uniformity becomes worse, and the orientation of the pores becomes worse. When rockburst similar materials rupture, they will break along the main weak structure surface and the local weak structure surface.

When the temperature is above $75.8^{\circ} \mathrm{C}$, due to dehydration, multiple groups of parallel oriented weak structural planes are formed. Fractures mainly occur along this, and partial ruptures occur along the local weak structural planes.

The influence of temperature on the mechanical properties of rock is related to the mineral properties and internal structure of the rock. Temperature changes will affect the mineral composition of the rock and the crystal lattice of the rock. The damage mechanism of rock under the action of temperature is quite different from that at room temperature.

From the curve in Figure 13 and the data in Table 13, it is found that the compressive strength of the similar materials of rockbursts is in the range of $20-90^{\circ} \mathrm{C}$. As the temperature increases, the uniaxial compressive strength and tensile strength of the similar materials increase continuously. In this temperature range, the compressive tensile ratio also shows a gradually increasing trend, indicating that as the temperature increases, the brittleness of the specimen and the energy inside the specimen gradually increase. With the increase in temperature, on the one hand, the phenomena of "thermal expansion and contraction" appear inside the rock mass, and the small cracks that originally existed in the rock mass gradually expand. On the other hand, when rockburst-like materials are only subjected to axial pressure, their internal stress gradually increases and the brittleness characteristics are more pronounced than when under lateral stress. The elastic strain energy in the original rock body is released at this time, and there is no lateral stress condition, which aggravates the rupture of the rockburst-like materials. The rupture causes damage outward in the form of kinetic energy, which may cause rockbursts. According to the energy theory, the occurrence of rockbursts can also be predicted and evaluated $[24,25]$.

The maximum elastic strain energy of the rock mass is defined by the following formula:

$$
E_{s}=\frac{\sigma_{c}^{2}}{(2 E)}
$$

where $E$ is the elastic modulus of the rock (GPa), $\sigma_{c}$ is the uniaxial compressive strength of the rock ( $\mathrm{MPa})$, and $E_{s}$ is the maximum stored strain energy of the specimen $\left(\mathrm{MJ} / \mathrm{m}^{3}\right)$.
The brittleness and energy changes in rockburst similar materials at different temperatures were calculated, and the results are shown in Figure 14.

From the experimental data for brittleness and energy of the model in Figure 14, it can be seen that as the temperature increases, the brittleness of the similar materials gradually increases and the maximum elastic strain energy of the specimen increases accordingly. From the above calculation and analysis, it can be observed that when the rockburst similar material initially fails, the small cracks inside the specimen continue to extend with the application of pressure, and the excess energy is transformed into kinetic energy. Under the action of temperature, the distance between the crystals inside the rock mass increases, and the internal voids of the rock mass increase owing to dislocation slippage. Under the coupling effect of temperature and stress, the damage and destruction of the internal basic structure of the test piece are exacerbated. According to the rockburst observation data, it can be concluded that the process of rockburst essentially involves the accumulation of energy in the early stage and its release under different conditions in the later stage. The process can be divided into three stages of energy accumulation, microcrack formation and propagation, and crack penetration and bursting.

The rock mass is in equilibrium before being excavated, and a large amount of elastic strain energy is stored inside. However, as the rock mass is excavated and construction disturbs the surrounding rock, the rock mass is gradually unbalanced. At great depths, a harsh environment with high ground temperature exists, which enhances the thermal sensitivity of the rock mass and aggravates the occurrence and extension of cracks. With the excavation, the radial stress of the rock mass decreases gradually. At the same time, the tangential stress increases, its effect coupled with the uneven thermal energy distribution begins to cause stress imbalance, and the local energy of the rock mass increases. Numerous microcracks exist in the rock mass. With the addition of the unbalanced internal stress of the rock mass, when the critical failure strength of the rock mass is smaller than its local stress, the microcracks in the rock mass gradually expand and increase. Simultaneously, the strain energy is released. When the energy released by the rock mass exceeds the energy required to form new fissures, the newly created microfissures grow immediately and gradually expand into cracks. Under high-temperature conditions and under the action of force loading, the cracks continue to expand and extend until they penetrate through the rock mass, resulting in rockbursts. At this time, the remaining elastic strain energy and thermal energy are transformed 


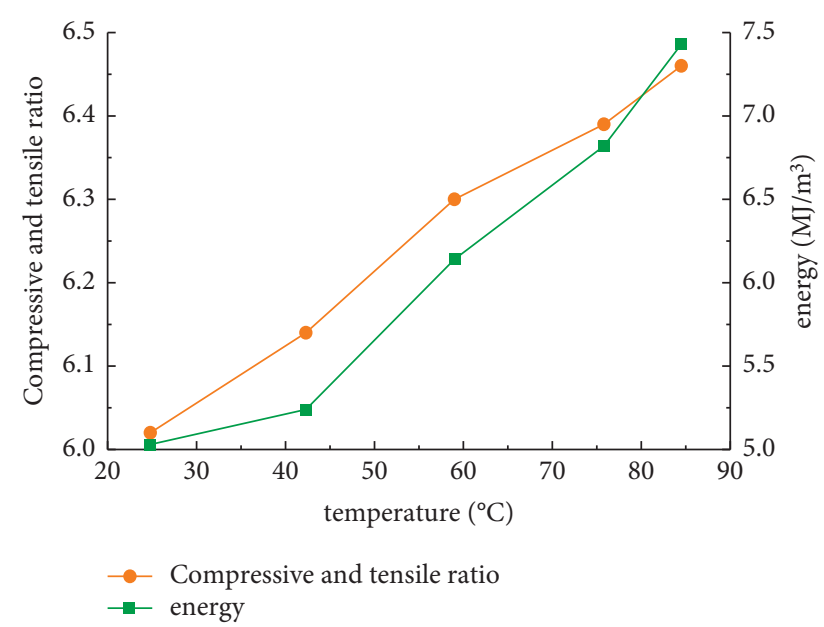

FIgURE 14: Variation of brittleness and energy of similar materials at different temperatures covered by the study.

into kinetic energy, which causes the damaged rock mass to leave the original rock mass through various ways, such as throw-out and ejection.

\section{Conclusion}

(1) An orthogonal test was conducted with quartz sand, iron powder, cement, gypsum, retarder, and waterreducing agent as the raw materials. Through the measurement of mechanical parameters, it can be concluded that the iron powder content and sand particle size have a great correlation with similar materials. The mechanical properties of the model play an important control role. To prepare a similar material model that is consistent with the rockburst tendency of white sandstone, it is necessary to reasonably adjust the ratio of gypsum to cement and control the amount of quartz sand. The main influencing factor of uniaxial compressive strength is iron powder content, the main influencing factor of tensile strength is iron powder content, the main influencing factor of elastic modulus is sand particle size, and the main influencing factor of compressive tensile ratio is sand particle size.

(2) From the results of the uniaxial compression test, it can be concluded that the failure forms of rockburst similar materials mainly include tension failure, shear failure, and combined tension and shear failure. From a macroscopic perspective, the failure of white sandstone is similar to that of the material model. Compound failure is dominant, and its manifestation is consistent with the failure mode of the original rock.

(3) A similar material ratio fitting was performed based on the test results, and the results showed the optimal composition of the white sandstone similar material model as quartz sand content of $36 \%$, iron powder content of $1.9 \%$, gypsum to cement ratio of $1.8: 1$, and sand particle size of 2-4 $\mathrm{mm}$.
(4) Based on the energy theory, it can be concluded that as the temperature increases and the stress changes, the brittle strength of similar materials gradually increases, and the maximum elastic strain energy of the rock mass increases accordingly, with the release of heat energy. It can be considered that the occurrence of a rockburst is closely related to the change in energy inside the rock mass. The rockburst process can be divided into three stages: the accumulation of energy, formation and propagation of microcracks, and penetration and bursting of cracks.

(5) It is concluded that the similar materials can effectively simulate the characteristics of white sandstone, and white sandstone is an ideal similar material of rockburst. They all show a strong rockburst tendency. It is found that, in a certain temperature range, with the increase of temperature, the fracture degree of white sandstone increases, the brittleness increases, the internal energy increases, and the anisotropy is obvious. It follows that the level of rockburst induced by high temperatures is increasing.

\section{Data Availability}

The data used to support the findings of this study are available from the corresponding author upon request.

\section{Conflicts of Interest}

The authors declare that they have no conflicts of interest.

\section{Acknowledgments}

This research was supported by the National Science Foundation of China (Grant no. 51978424).

\section{References}

[1] Y. Hu, H. F. Deng, J. L. Li, Y. C. Zhang, W. Wang, and Y.Y.Hu, "Study on the change characteristics and mechanism of fine structure of sandstone under water-rock interaction," Journal of Disaster Prevention and Mitigation Engineering, vol. 38, no. 2, pp. 265-273, 2018.

[2] Y. S. Dai, M. Y. Wang, Y. Wang, L. D. Wu, Z. C. Yan, and K. F. Jiang, "Discussion on similar materials based on deep rock engineering geomechanical model tests," Protection Works, vol. 1, pp. 73-78, 2016.

[3] T. B. Li, H. S. Pan, G. Q. Chen, and L. B. Meng, "Physical model test on temperature effect of rock burst in a tunnel under thermal-mechanical action," Journal of rock mechanics and Engineering, vol. 37, no. 2, pp. 261-273, 2018.

[4] Y. N. Xu, W. S. Xu, Y. H. Wang, G. H. Tan, and Y. Xu, "Rock burst simulation test and study of rock burst mechanism," Journal of rock mechanics and Engineering, vol. 10, pp. 1462-1466, 2002.

[5] A.-h. Lu, X.-b. Mao, and H.-s. Liu, "Physical simulation of rock burst induced by stress waves," Journal of China University of Mining and Technology, vol. 18, no. 3, pp. 401-405, 2008. 
[6] L. F. Wang, H. M. Tang, H. K. Chen, S. Q. Ye, and F. Tang, "Stability analysis of unstable rock blocks under the combined action of temperature and stress," Journal of Disaster Prevention and Mitigation Engineering, vol. 37, no. 6, pp. 871877, 2017.

[7] B. P. Simser, "Rockburst management in Canadian hard rock mines," Journal of Rock Mechanics and Geotechnical Engineering, vol. 11, no. 5, pp. 1036-1043, 2019.

[8] L. B. Jayasinghe, J. L. Shang, Z. Y. Zhao, and A. T. C. Goh, "Numerical investigation into the blasting-induced damage characteristics of rocks considering the role of in-situ stresses and discontinuity persistence," Computers and Geotechnics, vol. 116, 2019.

[9] W. Z. Chen, S. C. Li, X. B. Qiu, and W. S. Zhu, "Experimental and numerical analysis of rock crack propagation," Journal of Rock Mechanics and Engineering, vol. 01, pp. 18-23, 2003.

[10] L. H. Xu, J. H. Deng, and L. L. Wang, "Research on the damage evolution of rock materials based on DIC," Journal of Guizhou University, vol. 35, no. 3, pp. 110-115, 2018.

[11] J. Peng, M. Cai, G. Rong, C. B. Zhou, and X. G. Zhao, "Crack closure stress and damage evaluation of rock microcracks," Journal of Rock Mechanics and Engineering, vol. 34, no. 6, pp. 1091-1100, 2015.

[12] P. Cao, R. H. Cao, Y. L. Zhao, K. Zhang, C. Z. Pu, and W. C. Fan, "Rock crack propagation-fracture law and rheological characteristics," Journal of Nonferrous Metals, vol. 26, no. 8, pp. 1737-1762, 2016.

[13] F. Wang, M. Wang, Z. M. Zhu, H. Qiu, P. Ying, and X. Y. Wang, "Study on the evolution law of the whole process of dynamic growth of rock cracks under impact loading," Journal of Rock Mechanics and Engineering, vol. 38, no. 6, pp. 1139-1148, 2019.

[14] J. L. Wang, J. P. Chen, J. Yang, and J. S. Que, "The method and application of distance discriminant analysis for judging rockburst grade," Acta Rock and Soil Mechanics, vol. 30, no. 7, pp. 2203-2208, 2009.

[15] R. X. Xue, Z. Z. Liang, N. W. Xu, and L. L. Dong, "Rockburst prediction and stability analysis of the access tunnel in the main powerhouse of a hydropower station based on microseismic monitoring," International Journal of Rock Mechanics and Mining Sciences, vol. 126, no. 10, Article ID 104174, 2020.

[16] Y. J. Shen, T. L. Rong, G. S. Yang, Y. Yuan, Y. Yang, and X. Yu, "Experimental study on mixture ratio of similar sandstone materials," Advances in Water Resources and Hydropower Science and Technology, vol. 36, no. 4, pp. 75-79, 2016.

[17] L. Li, H. M. Jiang, X. B. Chen, and Z. X. Luo, "Model test and mechanical mechanism study of strain-type rockburst," Journal of rock mechanics and Engineering, vol. 37, no. 12, pp. 2733-2741, 2018.

[18] H. Zhou, J. Chen, C. Q. Zhang, Y. Zhu, J. J. Lu, and Y. Jiang, "Experimental study on material ratio of low strength and high brittleness rockburst model," Geomechanics, vol. 40, no. 6, pp. 2039-2049, 2019.

[19] S. B. Zhai, G. S. Su, S. D. Yin, B. Zhao, and L. B. Yan, "Rockburst characteristics of several hard brittle rocks: a true triaxial experimental study," Journal of Rock Mechanics and Geotechnical Engineering, vol. 12, no. 2, 2020.

[20] L. Xue, S. Qin, Q. Sun, Y. Wang, L. M. Lee, and W. Li, “A study on crack damage stress thresholds of different rock types based on uniaxial compression tests," Rock Mechanics and Rock Engineering, vol. 47, no. 4, pp. 1183-1195, 2014.

[21] B. Z. Xu, J. Li, Y. S. Liu, J. Y. Zou, and S. Y. Lv, "Study on mechanical properties of similar rockburst materials under static and dynamic loads," Science and Technology Bulletin, vol. 35, no. 4, pp. 83-88, 2019.

[22] S. F. Wang, L. Q. Huang, and X. B. Li, "Analysis of rockburst triggered by hard rock fragmentation using a conical pick under high uniaxial stress," Tunnelling and Underground Space Technology, vol. 96, Article ID 103195, 2020.

[23] G. S. Yang, Y. Wei, and Y. J. Shen, "Study on mechanical properties and strength prediction model of frozen saturated sandstone under triaxial compression," Journal of rock mechanics and Engineering, vol. 38, no. 4, pp. 683-694, 2019.

[24] X. J. Zhang and H. C. Zheng, "Experimental study on surrounding rock failure of rock burst-inclined tunnel," Mining Research and Development, vol. 31, no. 4, pp. 29-33, 2011.

[25] M. Cardu, D. Coragliotto, and P. Oreste, "Analysis of predictor equations for determining the blast-induced vibration in rock blasting," International Journal of Mining Science and Technology, vol. 29, no. 6, pp. 905-915, 2019. 